\title{
Microstructural control of the austenite stability in low- alloyed TRIP steels
}

DOI:

10.4028/www.scientific.net/SSP.172-174.196

Link to publication record in Manchester Research Explorer

\section{Citation for published version (APA):}

Blondé, R., Jimenez-Melero, E., Van Dijk, N. H., Brück, E., Zhao, L., Sietsma, J., \& Van Der Zwaag, S. (2011). Microstructural control of the austenite stability in low-alloyed TRIP steels. In Solid State Phenomena/Diffus Def Data Pt B (Vol. 172-174, pp. 196-201). Scientific.Net. https://doi.org/10.4028/www.scientific.net/SSP.172-174.196

\section{Published in:}

Solid State Phenomena|Diffus Def Data Pt B

\section{Citing this paper}

Please note that where the full-text provided on Manchester Research Explorer is the Author Accepted Manuscript or Proof version this may differ from the final Published version. If citing, it is advised that you check and use the publisher's definitive version.

\section{General rights}

Copyright and moral rights for the publications made accessible in the Research Explorer are retained by the authors and/or other copyright owners and it is a condition of accessing publications that users recognise and abide by the legal requirements associated with these rights.

\section{Takedown policy}

If you believe that this document breaches copyright please refer to the University of Manchester's Takedown Procedures [http://man.ac.uk/04Y6Bo] or contact uml.scholarlycommunications@manchester.ac.uk providing relevant details, so we can investigate your claim.

\section{OPEN ACCESS}




\title{
Microstructural control of the austenite stability in low-alloyed TRIP steels
}

\author{
R. Blondé ${ }^{1,2, a}$, E. Jimenez-Melero ${ }^{1, b}$, N.H. van Dijk ${ }^{1, c}, E$. Brück ${ }^{1, d}$, \\ L. Zhao ${ }^{2,3, e}$, J. Sietsma ${ }^{3, f}$, S. van der Zwaag ${ }^{4, g}$
}

${ }^{1}$ Fundamental Aspects of Materials and Energy, Faculty of Applied Sciences, Delft University of Technology, Mekelweg 15, 2629 JB Delft, The Netherlands

\author{
${ }^{2}$ Materials innovation institute, Mekelweg 2, 2628 CD Delft The Netherlands \\ ${ }^{3}$ Department of Materials Science and Engineering, Delft University of Technology, Mekelweg 2, \\ 2628 CD Delft, The Netherlands \\ ${ }^{4}$ Novel Aerospace Materials Group, Faculty of Aerospace Engineering, Delft University of \\ Technology, Kluyverweg 1, 2629 HS, Delft, The Netherlands

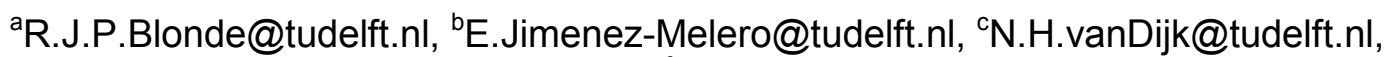 \\ dE.H.Brueck@tudelft.nl, eLie.Zhao@tudelft.nl, fJ.Sietsma@tudelft.nl, 9S.vanderZwaag@tudelft.nl
}

Key words: TRIP steels, Magnetization measurements, Synchrotron X-Ray Diffraction, Austenite stability

\begin{abstract}
We have performed in-situ magnetization and high-energy X-ray diffraction measurements on two aluminum-based TRIP steels from room temperature down to $100 \mathrm{~K}$ in order to evaluate amount and stability of the retained austenite for different heat treatment conditions. We have found that the bainitic holding temperature affects the initial fraction of retained austenite at room temperature but does not to influence significantly the rate of transformation upon cooling.
\end{abstract}

\section{Introduction}

Low-alloyed transformation-induced plasticity (TRIP) steels have attracted significant interest for automotive applications due to their high strength and formability [1]. A relatively complex twostage heat treatment leads to the presence of a significant amount of austenite $(<20 \%)$ in a metastable condition at room temperature [2]. The transformation of this metastable austenite into martensite can be induced by changes in temperature and/or an applied stress [3, 4]. This transformation seems to constitute the key process to obtain a high work hardening rate and a large uniform elongation in these materials $[2,4]$. We have recently derived a new equation that links the martensitic transformation temperature not only to the carbon content of the austenite grains but also to the grain size [5]. These two microstructural parameters are controlled by the heat treatment and the chemical composition of the material. The aim of this work is to maximize the amount of metastable austenite present in the room-temperature TRIP microstructure in order to improve the strength/ductility combination in these materials. To achieve this goal, we have varied the heat treatment parameters systematically in two aluminum-based TRIP steel grades. We have subsequently studied the thermal stability of the retained austenite by using two in-situ bulk techniques: magnetization measurements using a SQUID magnetometer [6] and high-energy X-ray diffraction at a synchrotron source $[5,7]$.

\section{Experimental}

Two TRIP steels grades with a different aluminum content were used: $0.188 \mathrm{C}-1.502 \mathrm{Mn}-0.254 \mathrm{Si}-$ 0.015P-0.443 Al $\left(\mathrm{Al}_{0.4}\right)$ and $0.218 \mathrm{C}-1.539 \mathrm{Mn}-0.267 \mathrm{Si}-0.018 \mathrm{P}-1.750 \mathrm{Al}\left(\mathrm{Al}_{1.8}\right)$ in wt.\%. Cylindrical samples with a length of $10 \mathrm{~mm}$ and a diameter of $5 \mathrm{~mm}$ were machined from the hot-rolled steel material and heat treated under vacuum using a Bähr 850a dilatometer. The samples were first annealed during 30 minutes at an intercritical temperature of $1098 \mathrm{~K}$ for $\mathrm{Al}_{0.4}$ and $1143 \mathrm{~K}$ for $\mathrm{Al}_{1.8}$, 
corresponding to approx. equal fractions of austenite and ferrite. The second stage was to quench the samples to a lower temperature where part of the intercritical austenite transformed into bainite. In order to assess the influence of the bainitic holding temperature $\left(\mathrm{T}_{\mathrm{bh}}\right)$ on the resultant TRIP microstructure at room temperature, we have prepared samples at three different temperatures: 623, 648 and $673 \mathrm{~K}$. At each temperature, the holding time was varied systematically from $30 \mathrm{~s}$ to 10 min. Finally, the material was quenched to room temperature. The austenite grains with sufficient stability did not transform into martensite during the final quenching step and remained in the room-temperature microstructure in a metastable condition. This specific heat treatment yielded a multiphase microstructure composed of ferrite, bainite and retained austenite. Fig. 1 shows the resultant microstructure of $\mathrm{Al}_{0.4}$ and $\mathrm{Al}_{1.8}$ at room temperature for two bainitic holding temperatures: 623 and $673 \mathrm{~K}$, and a holding time of $2 \mathrm{~min}$.

The thermal stability of retained austenite was studied by magnetization measurements using a SQUID magnetometer while cooling the material down to $100 \mathrm{~K}$ and heating back to room temperature in the presence of magnetic field of $5 \mathrm{~T}$. The difference in saturation magnetization of the TRIP steel containing the metastable austenite and the as-received ferritic steel is directly related to the volume fraction of the non-magnetic austenite [6]. The magnetization results are compared with those of our earlier in-situ high-energy $(\mathrm{E}=80 \mathrm{keV})$ X-ray diffraction measurements performed in transmission geometry at the beam line ID11 of the European Synchrotron Radiation Facility (Grenoble, France) [5, 7]. In this experiment, the sample was cooled from room temperature to $100 \mathrm{~K}$ in steps of $20 \mathrm{~K}$ using a nitrogen gas cryostream cooler. For each temperature step, the diffracted intensity from the different phases present in the microstructure was recorded on a two-dimensional detector placed behind the sample.

\section{Results and discussion}

\section{Austenite fraction at room temperature}

Fig. 2 shows the austenite fraction present at room temperature as a function of the bainitic holding temperature and time for the two studied TRIP compositions. Fig. $2 \mathrm{~b}$ shows that for the $\mathrm{Al}_{1.8}$ sample and $\mathrm{T}_{\mathrm{bh}}=673 \mathrm{~K}$, the austenite fraction increases with the holding time up to $2 \mathrm{~min}$ and then decreases slowly at longer times. By decreasing the bainitic temperature from 673 to $623 \mathrm{~K}$, the austenite fraction is reduced and the maximum in the austenite fraction is shifted towards longer times. By comparing Fig. 2a and b, the austenite fraction at room temperature turns out to be lower for the $\mathrm{Al}_{0.4}$ sample than for the $\mathrm{Al}_{1.8}$ sample at the same $\mathrm{T}_{\mathrm{bh}}$. The shape of the curve is similar for both compositions, but in the case of $\mathrm{Al}_{0.4}$ the maximum in austenite fraction appears at a shorter holding time of $1 \mathrm{~min}$ at $673 \mathrm{~K}$ and $2 \mathrm{~min}$ at $648 \mathrm{~K}$ and $623 \mathrm{~K}$. The retained austenite fraction decreases faster at longer holding times in the $\mathrm{Al}_{0.4}$ sample. 

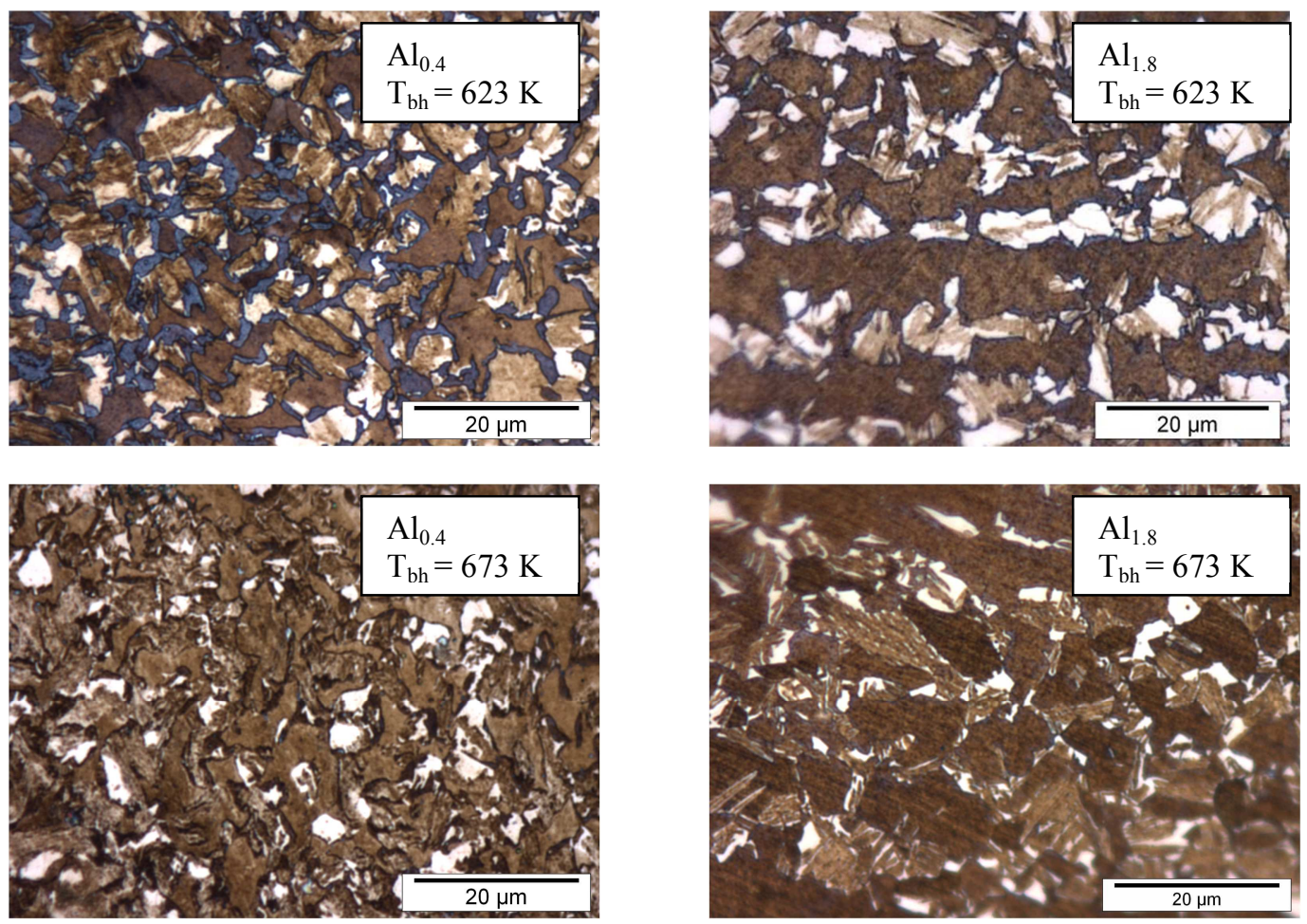

Fig. 1. Room-temperature microstructure of the two studied TRIP steel grades as revealed by optical microscopy. The micrographs correspond to a bainitic holding temperature of $\mathrm{T}_{\mathrm{bh}}=623$ and $673 \mathrm{~K}$ and a holding time of $2 \mathrm{~min}$. Austenite and martensite appear in white, while bainite and ferrite grains are shown in brown.

The microstructure of TRIP steels depends on the bainitic holding time. For short holding times, the austenite fraction at room temperature is relatively low due to a limited carbon enrichment during the bainitic transformation. Consequently, part of the austenite transforms into martensite during the quenching to room temperature. By increasing the holding time, the austenite fraction increases to reach a maximum value, which indicates the minimum degree of bainitic transformation necessary to hinder the partial transformation of the remaining austenite into martensite above room temperature. The position of this maximum depends on the bainitic holding temperature due to the influence of temperature on carbon diffusion. For longer times, a significant amount of bainite plates have grown into the austenite grains leading to a reduction in the austenite fraction with time. A second parameter that affects the austenite fraction at room temperature is the aluminum content. Aluminum increases the driving force of the bainitic transformation and retards the cementite formation during the bainitic holding step [5]. As shown in Fig. 2, the austenite fraction decreases with the aluminum content due to a reduced degree of bainite formation. Consequently, a lower carbon enrichment in austenite is expected. For longer holding times, the austenite fraction seems to tend to zero. This may indicate the possible formation of carbides in the TRIP sample with only 0.4 wt.\% Al at long holding times. A higher bainitic holding temperature leads to faster bainite transformation kinetics, and therefore induces a faster austenite stabilization with a maximum point at $673 \mathrm{~K}$ for $1 \mathrm{~min}$ instead of $2 \mathrm{~min}$ for the $\mathrm{Al}_{0.4}$ sample. 
$\boldsymbol{a}$

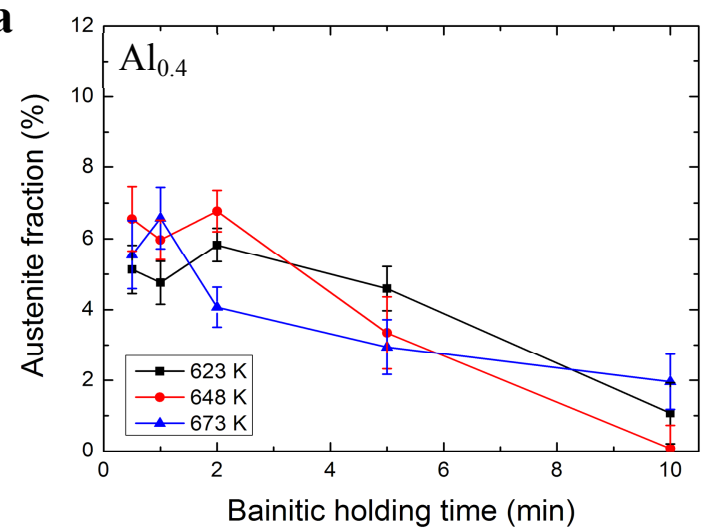

b

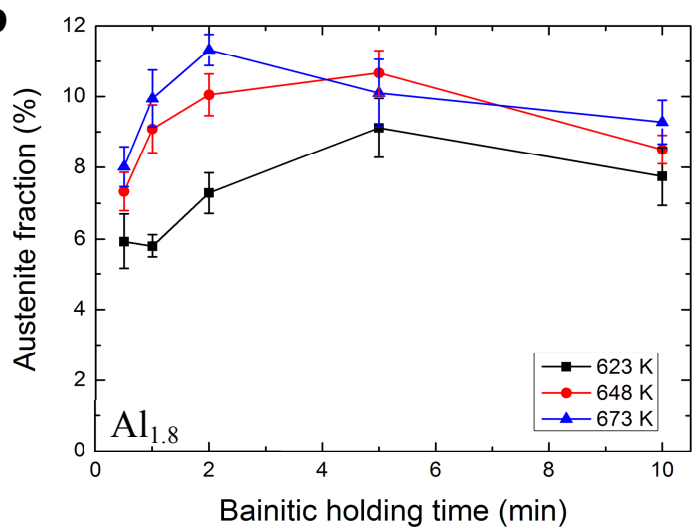

Fig. 2. Variation of the austenite fraction at room temperature with the bainitic holding temperature and time for (a) $\mathrm{Al}_{0.4}$ and (b) $\mathrm{Al}_{1.8}$.

\section{Austenite stability below room temperature}

The heat treatment leading to the highest fraction of retained austenite at room temperature $\left(\mathrm{T}_{\mathrm{bh}}=673 \mathrm{~K}\right.$ for $2 \mathrm{~min}$ in $\mathrm{Al}_{1.8}$ ) was selected as base material to study the thermal stability of the retained austenite at lower temperatures. For comparison, the bainitic holding temperature was varied from 673 to $623 \mathrm{~K}$ for a fixed holding time of $2 \mathrm{~min}$ for both chemical compositions. Fig. 3a and $\mathrm{b}$ shows the austenite fraction as a function of the temperature during cooling down to $100 \mathrm{~K}$. In all cases, the austenite fraction decreases during the cooling process, what indicates that part of the metastable austenite has transformed into martensite. The transformation starts at $250-275 \mathrm{~K}$ irrespective of the bainitic holding temperature and the chemical composition, and stops in the temperature range of 120-150 K. As expected, the austenite fraction does not change any further upon heating the material back to room temperature. An austenite fraction of $1.4 \%$ transforms thermally into martensite in the $\mathrm{Al}_{0.4}$ sample for all bainitic holding temperatures, while the transformed austenite fraction is around $2.3 \%$ in the $\mathrm{Al}_{1.8}$ sample. The bainitic temperature turns out to have a weak influence on the austenite stability when varied from 623 to $673 \mathrm{~K}$, only on the initial austenite fraction before cooling. Moreover, a fraction of the initial metastable austenite grains still remain untransformed at the lowest temperature of $100 \mathrm{~K}$ in all samples. The average austenite carbon content $\left(\left\langle x_{c}^{\gamma}\right\rangle\right)$ and grain volume $\left(\left\langle V_{\gamma}\right\rangle\right)$ have been compared before and after cooling down to $100 \mathrm{~K}$ using high-energy X-ray diffraction [5], see Table 1 . These data indicate that only small grains with a high carbon content remain untransformed at $100 \mathrm{~K}$. 
$\mathbf{a}$

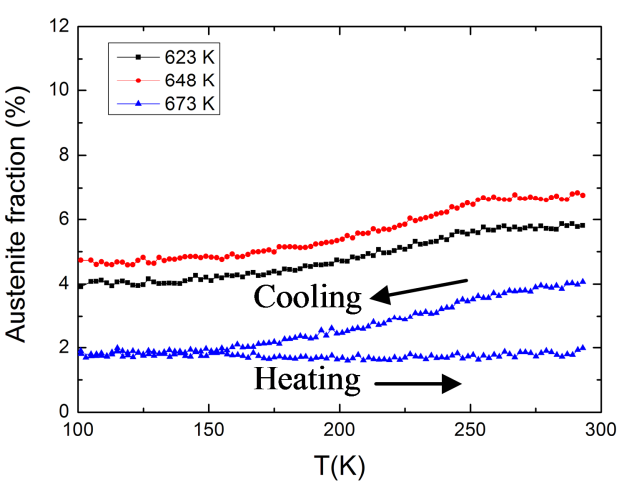

c

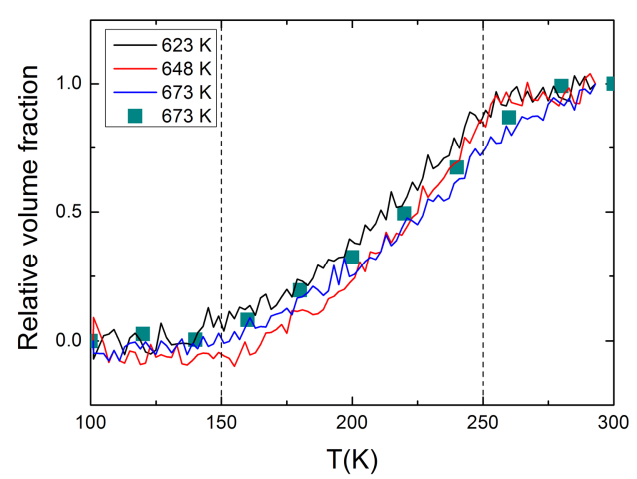

b

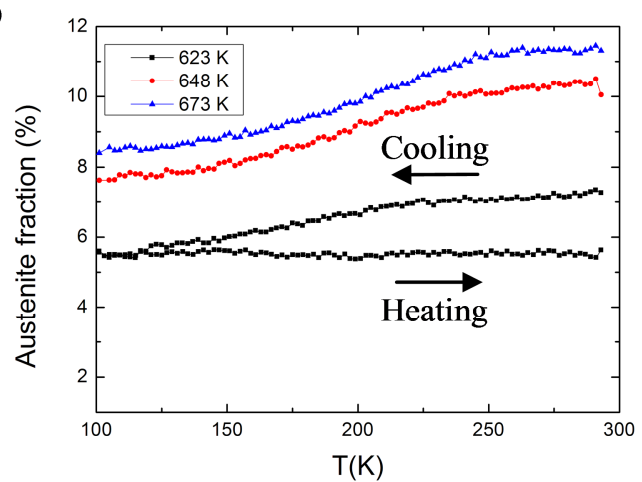

$\mathbf{d}$

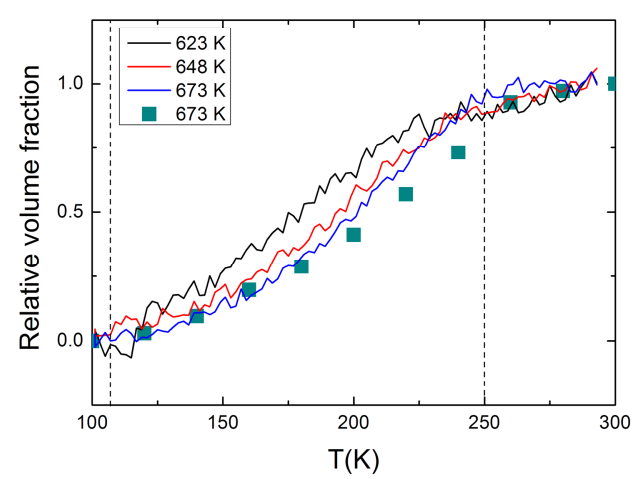

Fig. 3. Evolution of the austenite fraction as a function of the temperature for (a) $\mathrm{Al}_{0.4}$ and (b) $\mathrm{Al}_{1.8}$. The relative volume fraction as a function of the temperature is shown in (c) and (d) for both chemical compositions and for a bainitic holding time of $2 \mathrm{~min}$. The green dots correspond to the data obtained by in-situ X-ray diffraction (taken from ref. [7]). The dashed line indicates the temperature region where the austenite transforms into thermal martensite.

Finally, in Fig. 3c and d the comparison between the results of the magnetization measurements and those of the in-situ X-ray diffraction experiment is displayed. A very satisfactory agreement is obtained between both techniques. All the curves have the same slope, what means that the transformation behaviour is similar for all process routes for a selected chemical composition. The martensitic transformation occurs in a narrower temperature range between $150 \mathrm{~K}$ and $250 \mathrm{~K}$ for $\mathrm{Al}_{0.4}$ sample. A higher aluminum content is found to induce a more gradual transformation of the austenite during cooling down to $100 \mathrm{~K}$.

Table 1. Average grain volume $\left(\left\langle V_{\gamma}\right\rangle\right)$ and carbon content $\left(\left\langle x_{c}^{\gamma}\right\rangle\right)$ of austenite before and after cooling down to $100 \mathrm{~K}$ for both compositions, taken from ref. [5]. The width of the distribution (standard deviation) is indicated in parenthesis.

\begin{tabular}{|ccccc|}
\hline & \multicolumn{2}{c}{$<V_{\gamma}>\left(\mu m^{3}\right)$} & \multicolumn{2}{c|}{$<x_{c}^{\gamma}>(w t . \%)$} \\
\hline Material & Before & After & Before & After \\
\hline $\mathrm{Al}_{0.4}$ & $11.8(6.5)$ & $7.8(2.9)$ & $0.92(0.10)$ & $1.01(0.16)$ \\
\hline $\mathrm{Al}_{1.8}$ & $20.9(12.2)$ & $11.5(7.2)$ & $0.81(0.14)$ & $1.02(0.11)$ \\
\hline
\end{tabular}




\section{Conclusions}

The thermal stability of retained austenite in two aluminum-based TRIP steels was studied by a combination of two in-situ bulk experimental techniques: magnetization measurements and highenergy X-ray diffraction. The main conclusions of the present study are:

1. The austenite fraction at room temperature increases with the bainitic holding time up to a maximum value, and then decreases slowly for longer times. If the bainitic holding temperature is lowered, this maximum is shifted towards longer holding times. A decrease in the aluminum content causes a reduction in the austenite fraction and the maximum occurs at shorter holding times.

2. The thermal stability of the retained austenite does not vary significantly with the bainitic holding temperature in the range of $623-673 \mathrm{~K}$ for each of the two studied TRIP steels. An increase in the aluminum content leads to a more gradual transformation of the metastable austenite.

3 A certain amount of austenite remains untransformed at $100 \mathrm{~K}$ in all the studied samples. These remaining austenite grains are too stable due to a high carbon content and a small grain size that gives a very low value for their martensite transformation temperature.

4. In-situ magnetization and high-energy X-ray diffraction measurements show similar results with respect to the transformation behavior of the metastable austenite below room temperature. Both techniques are successful in monitoring in-situ the martensite transformation of a small amount of retained austenite.

\section{Acknowledgement}

This research was carried out under the project number M41.5.08313 in the framework of the Research Program of the Materials innovation institute M2i (www.m2i.nl).

\section{References}

[1] M. Militzer, Science 298 (2002) 975.

[2] P.J. Jacques, Curr. Opin. Solid State Mater. Sci. 8 (2004) 259.

[3] M.R. Berrahmoune, S. Berveiller, K. Inal, A. Moulin, E. Patoor, Mater. Sci. Eng. A 378 (2004) 304.

[4] I.B. Timokhina, P.D. Hodgson, E.V. Pereloma, Metall. Mater. Trans. A 35 A (2004) 2331.

[5] E. Jimenez-Melero, N.H. van Dijk, L. Zhao, J. Sietsma, S.E. Offerman, J.P. Wright, S. van der Zwaag, Acta Mater. 57 (2009) 533.

[6] L. Zhao, N.H. van Dijk, E. Brück, J. Sietsma, S. van der Zwaag, Mater. Sci. Eng. A 313 (2001) 145.

[7] N.H. van Dijk, A.M. Butt, L. Zhao, J. Sietsma, S.E. Offerman, J.P. Wright, S. van der Zwaag, Acta Mater. 53 (2005) 5439. 
Solid-Solid Phase Transformations in Inorganic Materials 10.4028/www.scientific.net/SSP.172-174

Microstructural Control of the Austenite Stability in Low-Alloyed TRIP Steels 10.4028/www.scientific.net/SSP.172-174.196 